\title{
Pleurodesis in malignant pleural effusions: a randomized study of tetracycline versus bleomycin
}

\author{
E. Martínez-Moragón*, J. Aparicio**, M.C. Rogado*, J. Sanchis*, \\ F. Sanchis*, V. Gil-Suay*
}

Pleurodesis in malignant pleural effusions: a randomized study of tetracycline versus bleomycin. E. Martínez-Moragón, J. Aparicio, M.C. Rogado, J. Sanchis, F. Sanchis, V. Gil-Suay. OERS Journals Ltd 1997.

ABSTRACT: Malignant pleural effusions are commonly managed with tube thoracostomy drainage followed by chemical pleurodesis. Both tetracycline and bleomycin have been shown to be effective for intrapleural instillation, although neither agent has definitively proved advantages over the other. The aim of the present study was to compare these two agents in terms of response rate and toxicity profile.

A prospective, randomized trial was carried out in a single centre. Between May 1993 and January 1996, 62 evaluable patients with proved malignant pleural effusion were allocated to receive either intrapleural tetracycline $(1.5 \mathrm{~g})$ or bleomycin $(60 \mathrm{mg})$ after the same drainage procedure. Demographic, clinical and fluid parameter data were comparable in both groups. Response was evaluated at 1, 3 and 6 months after pleurodesis.

Mean survival and time to relapse did not differ between the two groups. No statistically significant differences were found in terms of efficacy at each evaluation time. Overall, $16(52 \%)$ and $20(64 \%)$ patients had a recurrence of pleural effusion during follow-up in the tetracycline and bleomycin arms, respectively. Fever was most common in bleomycin-treated patients $(p=0.024)$ while pain was most frequent in the tetracycline arm (nonsignificant).

Since no study agent was superior to the other in this trial, we suggest that economic costs, drug availability and medical skill should be considered in the choice of a sclerosing agent.

Eur Respir J 1997; 10: 2380-2383.

Malignant pleural effusions are a common medical problem in patients with cancer. The usual treatment of these recurrent, symptomatic effusions is intrapleural instillation of a chemical substance in an attempt to produce pleurodesis. Several agents have been employed for this purpose. However, there have been very few controlled trials to ascertain which one is superior in terms of response [1].

Tetracycline, talc and bleomycin are considered the primary sclerosing agents [2]. Talc appears to be the most effective and least expensive; however, it is more difficult to employ, frequently requiring pleuroscopy or even thoracostomy for instillation [3]. Therefore, tube thoracostomy drainage followed by application of tetracycline or bleomycin is the commonest method of chemical pleurodesis. Although the response rates to tetracycline and bleomycin seem comparable [3], there have been few randomized comparative trials [4-6]. The purpose of the present study was to determine, within a single institution, whether any differences exist between these sclerosing agents in terms of efficacy or side-effects.

\section{Materials and methods}

\section{Study design}

A prospective, randomized study was planned to compare intrapleural tetracycline $(1.5 \mathrm{~g})$ and bleomycin $(60$
Depts of *Pneumology and **Medical Oncology, La Fe University Hospital, Valencia, Spain.

Correspondence: J. Aparicio Servicio de Oncología Médica Hospital Universitario La Fe Avda. Campanar, 21 E-46009 Valencia Spain

Keywords: Bleomycin pleural effusion pleurodesis tetracycline

Received: October 301996 Accepted after revision May 101997 $\mathrm{mg}$ ) for the treatment of malignant pleural effusions. The same investigators performed all procedures in a single institution. Approval was granted for the study by the Ethics Committee of the hospital.

\section{Eligibility}

Patients eligible for the study were those with malignant pleural effusion causing respiratory symptoms, proved by cytological examination or pleural biopsy, and an expected survival of at least 1 month with a Karnofsky score of 50 or more. Although previous drainage procedures were not considered as grounds for exclusion, no prior intrapleural instillation therapy was allowed. Patients who had had chest radiotherapy during the preceding 2 weeks, and those who had previously received systemic bleomycin, were also excluded. No changes in systemic chemotherapy or hormonotherapy were permitted in the 4 weeks prior to study, although new therapies could be initiated after pleurodesis. Patients in whom complete lung expansion was not possible, due to either obstructive atelectasis or loculate effusion, were considered ineligible. All patients denied allergies to the study drugs.

\section{Treatment}

After giving informed consent, patients were randomly assigned by computer to one of two groups. The protocol 
used was tube thoracostomy suction drainage until reexpansion of the lung, and the amount of fluid drained was less than $100 \mathrm{~mL} \cdot$ day $^{-1}$. Tetracycline $(1.5 \mathrm{~g}$ diluted in $100 \mathrm{~mL}$ normal saline solution plus $9 \mathrm{~mL} \mathrm{5 \%} \mathrm{lig-}$ nocaine) was then instilled intrapleurally in the first group of patients. Similarly, bleomycin $(60 \mathrm{mg}$ diluted in $100 \mathrm{~mL}$ normal saline solution) was instilled in the second group of patients. Following this, the tube was clamped for $4 \mathrm{~h}$, but the patient's position was not rotated. Finally, the tube was unclamped and suction drainage was resumed until the fluid obtained was less than 100-150 mL.day ${ }^{-1}$. At this time, the chest tube was removed. Adverse effects of the procedure were systematically registered.

\section{Evaluation of response}

Before pleurodesis, the size of the pleural effusion in a posteroanterior chest radiograph was catalogued as "moderate", when extending from the diaphragm to the pulmonary hilum, and "massive", when exceeding the hilar region. Patients were followed up with chest radiographs at 1, 3 and 6 months after pleurodesis. Responses were classified as: 1) complete (no clinical or radiological recurrence of pleural effusion); 2) partial (small amount of fluid reaccumulation in the chest radiograph, but no symptoms); and 3) failure (reaccumulation of fluid causing symptoms or needing thoracocentesis) [7, 8].

\section{Statistical analysis}

Both study groups were compared with respect to demographic features, performance status, site of primary tumour, number of metastases and disease characteristics. The t-test was used for continuous variables and the Chi-squared or Fisher's exact tests, when appropriate, for comparison of proportions. Response rates between the two agents were compared at each evaluation (1, 3 and 6 months) using the Chi-squared test. Time to recurrence and survival were analysed using the Kaplan-Meier method [9], and curves were compared with the Mantel-Haenszel test [10]. All statistical comparisons between bleomycin and tetracycline were two-sided and carried out at the 0.05 significance level.

\section{Results}

Between May 1993 and January 1996, 70 consecutive patients entered the study. Thirty five patients were randomly assigned to the tetracycline-treated group and 35 to the bleomycin-treated group. Eight patients (11\%) were ineligible due to rapid progression of systemic disease and death (five) or lack of follow-up (three). Thus, 62 patients were eligible for analysis (31 included in the tetracycline-treated group and 31 in the bleomycintreated group).

Demographic and primary disease characteristics are summarized in table 1. The majority of patients had lung or breast cancer, with one other site of metastases, along with pleural malignancy, and a good initial performance status. Nearly half had received prior systemic chemo-
Table 1. - Characteristics of patients in both treatment groups

\begin{tabular}{|c|c|c|c|c|}
\hline & \multicolumn{2}{|c|}{$\begin{array}{l}\text { Tetracycline } \\
(\mathrm{n}=31)\end{array}$} & \multicolumn{2}{|c|}{$\begin{array}{l}\text { Bleomycin } \\
\quad(\mathrm{n}=31)\end{array}$} \\
\hline Age yrs* & $60 \pm 15$ & $(30-80)$ & $58 \pm 11$ & $(34-79)$ \\
\hline Male/female & $12 / 19$ & & $15 / 16$ & \\
\hline Karnofsky score ${ }^{+}$ & 70 & $(50-90)$ & 70 & $(60-90)$ \\
\hline \multicolumn{5}{|c|}{ Primary site of tumour $n$} \\
\hline Breast & 10 & & 7 & \\
\hline Lung & 7 & & 10 & \\
\hline Rectal & 0 & & 1 & \\
\hline Stomach & 2 & & 1 & \\
\hline Ovarian & 1 & & 1 & \\
\hline Unknown & 6 & & 3 & \\
\hline Lymphoma & 2 & & 4 & \\
\hline Mesothelioma & 1 & & 1 & \\
\hline Osteosarcoma & 1 & & 2 & \\
\hline Thyroid & 0 & & 1 & \\
\hline Melanoma & 1 & & 0 & \\
\hline \multicolumn{5}{|l|}{ Metastatic sites n } \\
\hline 0 & 7 & (22) & 6 & (19) \\
\hline 1 & 13 & (41) & 11 & (35) \\
\hline 2 & 7 & (22) & 8 & (25) \\
\hline$\geq 3$ & 2 & (6) & 4 & (13) \\
\hline Unknown & 2 & (6) & 2 & (6) \\
\hline Prior surgery & 11 & (35) & 10 & (32) \\
\hline Prior chemotherapy & 14 & (45) & 13 & (42) \\
\hline Prior irradiation & 7 & (22) & 8 & (25) \\
\hline
\end{tabular}

Values are expressed as absolute number of patients, and percentage in parenthesis, unless otherwise noted. *: mean \pm SD (range); +: median (range).

therapy and 32-35\% underwent surgery for their primary tumour. Time since the diagnosis of cancer to the onset of pleural effusion was $28 \pm 36$ months for the tetracycline-treated group versus $22 \pm 42$ months for the bleomycin-treated group. There were no significant differences between the two groups with regard to demographic characteristics, primary disease or prior treatment. Clinical and radiographic features are shown in table 2, and pleural fluid parameters in table 3. Again, these figures were very similar in both study arms.

The mean volume of pleural fluid drained before pleurodesis was significantly greater in the bleomycin-treated

Table 2. - Presenting symptoms and radiographic features

\begin{tabular}{|c|c|c|}
\hline & $\begin{array}{l}\text { Tetracycline } \\
\quad(\mathrm{n}=31)\end{array}$ & $\begin{array}{l}\text { Bleomycin } \\
\quad(n=31)\end{array}$ \\
\hline \multicolumn{3}{|l|}{ Symptoms } \\
\hline Dyspnoea & $31(100)$ & $31(100)$ \\
\hline Chest pain & $16 \quad(51)$ & $18 \quad(58)$ \\
\hline Cough & $19 \quad(61)$ & $17 \quad(55)$ \\
\hline Haemoptysis & $2 \quad(6)$ & $2 \quad(6)$ \\
\hline \multicolumn{3}{|l|}{ Chest radiograph } \\
\hline Only pleural effusion & $11 \quad(35)$ & (38) \\
\hline Lung masses & (16) & (25) \\
\hline Pulmonary nodules & (16) & (9) \\
\hline Pleural masses & (16) & (13) \\
\hline Loss of lung volume & $5 \quad(16)$ & (13) \\
\hline \multicolumn{3}{|l|}{ Size of pleural effusion } \\
\hline Moderate & $(58)$ & (64) \\
\hline Massive & (42) & (35) \\
\hline
\end{tabular}

Values are presented as number of patients, and percentage in parenthesis. 
Table 3. - Pleural fluid parameters before pleurodesis

\begin{tabular}{lcc}
\hline & $\begin{array}{c}\text { Tetracycline } \\
(\mathrm{n}=31)\end{array}$ & $\begin{array}{c}\text { Bleomycin } \\
(\mathrm{n}=31)\end{array}$ \\
\hline Malignant cytology* & $17(55)$ & $17(55)$ \\
Fluid $\mathrm{pH}$ & $7.31 \pm 0.12$ & $7.29 \pm 0.14$ \\
Glucose $\mathrm{mg} \cdot \mathrm{dL}^{-1}$ & $113.9 \pm 84$ & $117.3 \pm 52$ \\
Protein levels g.dL $\mathrm{dL}^{-1}$ & $4.49 \pm 0.78$ & $4.42 \pm 0.74$ \\
Pleural LDH U.L & $864 \pm 1010$ & $784 \pm 680$ \\
\hline
\end{tabular}

*: All other cases were diagnosed through pleural biopsy. Data are expressed as number of patients (percentage) or as mean \pm SD. LDH: lactate dehydrogenase.

group, as was mean duration of chest drainage after pleurodesis in the tetracycline-treated group (table 4). However, these differences were not clinically relevant. There were no complications of tube thoracostomy. Adverse experiences were reported in $15(48 \%)$ bleomycintreated patients and $17(55 \%)$ tetracycline-treated patients. Pain was usually self-limiting and, depending upon the severity, managed with paracetamol or opiates. There were no significant differences in the incidence of side-

Table 4. - Procedure-related aspects and side-effects

\begin{tabular}{|c|c|c|}
\hline & $\begin{array}{c}\text { Tetracycline } \\
(\mathrm{n}=31)\end{array}$ & $\begin{array}{l}\text { Bleomycin } \\
\quad(n=31)\end{array}$ \\
\hline \multicolumn{3}{|l|}{ Interval between diagnosis } \\
\hline effusion months & $1.7 \pm 2.3$ & $2.6 \pm 6$ \\
\hline $\begin{array}{l}\text { Thoracocenteses in the } \\
\text { last } 3 \text { months } n\end{array}$ & $1.2 \pm 0.7$ & $1.0 \pm 0.9$ \\
\hline Total chest drainage fluid $\mathrm{mL}$ & $2669 \pm 921$ & $3322 \pm 1161^{+}$ \\
\hline \multicolumn{3}{|l|}{ Drainage time days } \\
\hline Before pleurodesis & $1.12 \pm 0.34$ & $1.09 \pm 0.39$ \\
\hline After pleurodesis & $1.41 \pm 0.7$ & $1.09 \pm 0.3^{\#}$ \\
\hline \multicolumn{3}{|l|}{ Adverse effects of pleurodesis } \\
\hline Pain during instillation & $10(32)$ & 7 (22) \\
\hline Fever & $0 \quad(0)$ & $6(19) \dagger$ \\
\hline Nausea/vomiting & 1 (3) & $1 \quad(3)$ \\
\hline Vegetative reaction & $0 \quad(0)$ & $1 \quad(3)$ \\
\hline Delayed pain & $16(51)$ & $10(32)$ \\
\hline
\end{tabular}

$+: \mathrm{p}=0.017 ; \#: \mathrm{p}=0.019 ; \dagger: \mathrm{p}=0.024$, versus tetracycline-treated group. Data are expressed as number of patients (percentage) or as mean \pm SD.

Table 5. - Response to chemical pleurodesis

\begin{tabular}{lrrrrr}
\hline Response & Tetracycline & \multicolumn{3}{c}{ Bleomycin } & p-value* \\
& $\mathrm{n}(\%)$ & $\mathrm{n}$ & $(\%)$ & \\
\hline 1 month evaluation & & & & & \\
NE & 0 & 0 & & \\
CR & 16 & $(52)$ & 14 & $(45)$ & 0.799 \\
PR & 9 & $(29)$ & 12 & $(39)$ & \\
Failure & 6 & $(19)$ & 5 & $(16)$ & \\
3 month evaluation & & & & & \\
NE & 7 & 6 & & \\
CR & 15 & $(62)$ & 11 & $(44)$ & 0.312 \\
PR & $5(21)$ & 12 & $(48)$ & \\
Failure & 4 & $(17)$ & 2 & $(8)$ & \\
6 month evaluation & & & & & \\
NE & 14 & 11 & & \\
CR & 14 & $(82)$ & 10 & $(50)$ & 0.087 \\
PR & $2(12)$ & 6 & $(30)$ & \\
Failure & 1 & $(6)$ & 4 & $(20)$ & \\
\hline
\end{tabular}

*: for comparison of CR with PR and Failure combined. NE: not evaluable (chest radiography not performed, patient lost to follow-up, or death); CR: complete response; PR: partial response.

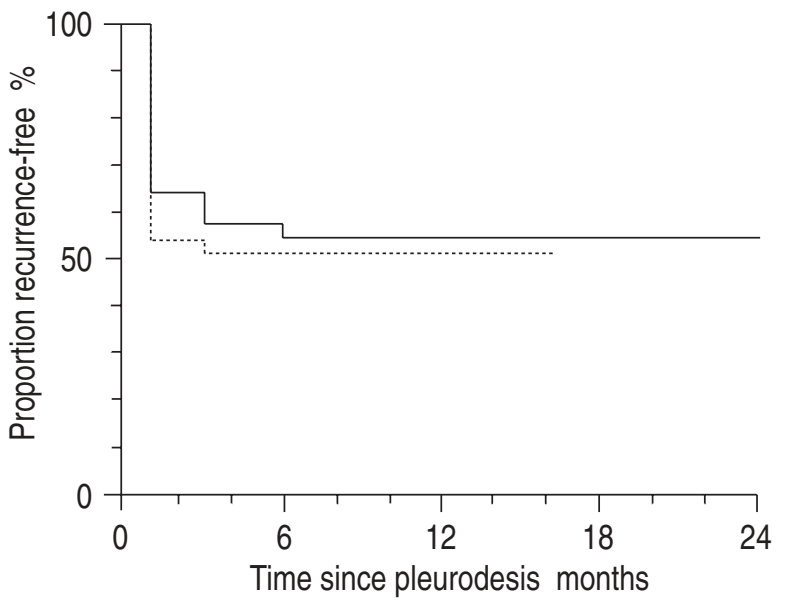

Fig. 1. - Actuarial curves showing the realpse time of pleural effusion after pleurodesis. There was no significant difference between treatments. $\longrightarrow$ : bleomycin; ………....... : tetracycline.

effects between the treatment groups, except for fever occurring more frequently in the bleomycin group (table 4). Fever reached $38-39^{\circ} \mathrm{C}$ and lasted for 1 day. Antipyretics were not administered routinely, and no post-treatment infections were identified. No severe or life-threatening adverse experiences were noted in this study.

Table 5 shows the response rate to both agents at each evaluation point. The percentage of failures did not differ between the two groups. A trend for a higher complete response rate was noted in the tetracycline arm. Nevertheless, it was not statistically significant at 1, 3 and 6 months after pleurodesis.

Overall, 16 and 20 patients had a recurrence of pleural effusion during follow-up in the tetracycline and bleomycin arms, respectively. The recurrences included two of the $10(20 \%)$ partial responses that became failures in the tetracycline group, and four of the $13(31 \%)$ in the bleomycin group. Mean time to relapse was $32 \pm 16$ days for tetracycline and $36+41$ days for bleomycin, with overlapping actuarial curves (fig. 1). Sixteen patients died in each arm, with a mean follow-up time of 7 months. Median survival was 13 months in the tetracycline arm and 9 months in the bleomycin arm (nonsignificant; fig. 2).

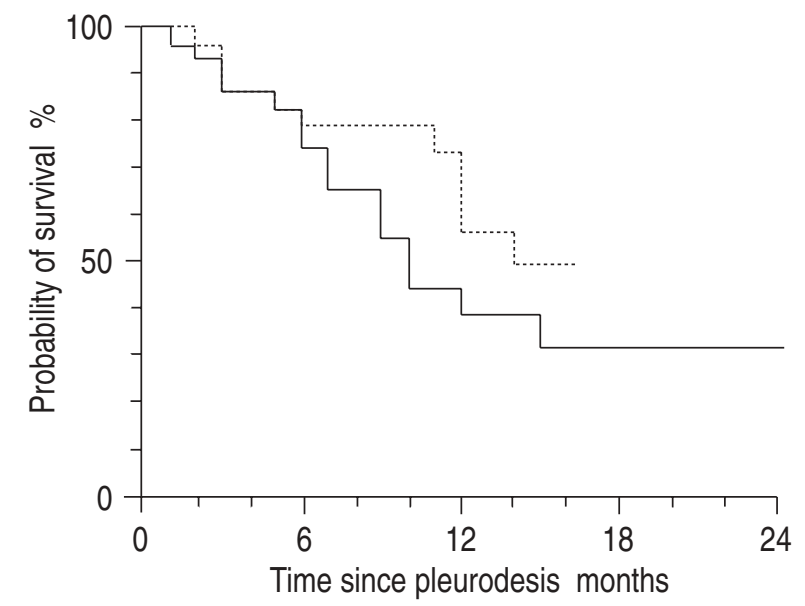

Fig. 2. - Probability of survival for all patients in both arms. There was no significant difference between treatments. ................: tetracycline. 


\section{Discussion}

The prognosis of patients with malignant pleural effusion is poor, although it varies depending on the histological features of the primary tumour. Chemical pleurodesis is a palliative treatment intended to obliterate the pleural space. In the last two decades, tetracycline has become the sclerosing agent of choice because of its safety, inexpensiveness and consistent efficacy [11-13]. Although it has been less extensively studied, intrapleural bleomycin is an alternative agent for pleurodesis. Bleomycin seems to cause less pain during instillation, but is more expensive than tetracycline. Data on effectiveness are not conclusive $[8,14,15]$.

There are only three randomized trials comparing these two agents in the literature. Two of them showed no significant differences in response rates, although the number of patients was small $[4,5]$. In a recent, multicentre study, bleomycin was more effective at both 30 and 90 day evaluations [6]. Toxicity was similar between groups in all these trials. Unfortunately, drug doses differed among studies $(0.5-1 \mathrm{~g}$ for tetracycline; $60-89 \mathrm{mg}$ for bleomycin).

In the present study, both agents seem equivalent in terms of efficacy. A trend for a higher complete response rate in the tetracycline arm might be related to the higher doses used $(1.5 \mathrm{~g})$, as suggested by its mechanism of action. In an experimental model, intrapleural tetracycline acts in a dose-dependent way, stimulating mesothelial cells to release a growth-factor-like activity for fibroblasts that induces pleural fibrosis $[16,17]$. By contrast, the injection of bleomycin was ineffective in creating pleural fibrosis in rabbits with normal pleura, thus suggesting a possible antineoplastic effect [18]. GRAVELYN et al. [12] proposed that the use of larger doses of tetracycline $(\geq 1 \mathrm{~g})$ may increase the probability of successful pleurodesis. In a previous retrospective study, the authors showed that tetracycline doses of $1.5 \mathrm{~g}$ were more effective than $1 \mathrm{~g}$ (although differences were not statistically significant) without increasing toxicity [19]. Therefore, we selected the first dosage for the present trial.

Pain is the most commonly reported side-effect during the instillation of tetracycline, and in the following days. In the present and other studies $[5,6]$, the incidence of pain was not significantly different between both groups, probably due to the systematic inclusion of a local anaesthetic within the tetracycline preparation. Fever was most frequent among bleomycin-treated patients, as reported in previous [5], but not in all [6], randomized studies. Serious complications were not seen in our trial. Overall, toxicity of pleurodesis with both agents was mild and easily manageable, and most of the chest tubes were withdrawn after 1 day.

The present study confirms that patients with pleural effusion undergoing pleurodesis have a median survival of about 12 months, with a mean time to recurrence of 30 days. Tetracycline and bleomycin are equally effective. It is remarkable that not only patients with complete responses benefit from sclerotherapy, since many of those with partial responses never become failures (i.e. they never need retreatment).

With similar efficacy and toxicity, the choice of one agent over the other should take into account other factors such as drug availability, economic costs and medical skill. At our institution, bleomycin costs are 2.6 times greater than those of tetracycline at the doses used in this study. If tetracycline is selected, we recommend the use of a $1.5 \mathrm{~g}$ dosage.

\section{References}

1. Reid PT, Rudd RM. Management of malignant pleural effusion. Thorax 1993; 48: 779-780.

2. Moffett MJ, Ruckdeschel JC. Bleomycin and tetracycline in malignant pleural effusions: a review. Semin Oncol 1992; 19: 59-63.

3. Walker-Renard PB, Vaughan LM, Shan SA. Chemical pleurodesis for malignant pleural effusions. Ann Intern Med 1994; 120: 56-64.

4. Gupta N, Opfell RW, Padova J, Margileth D, Souadjian J. Intrapleural bleomycin versus tetracycline for control of malignant pleural effusion: a randomized study. Proc Am Assoc Cancer Res 1980; 21: 366.

5. Kessinger A, Wigton RS. Intracavitary bleomycin and tetracycline in the management of malignant pleural effusions: a randomized study. J Surg Oncol 1987; 36: 81-83.

6. Ruckdeschel JC, Moores D, Lee JY, et al. Intrapleural therapy for malignant pleural effusions: a randomized comparison of bleomycin and tetracycline. Chest 1991; 100: $1528-1535$.

7. Sanchez-Armengol A, Rodriguez-Panadero F. Survival and talc pleurodesis in metastatic pleural carcinoma, revisited. Report of 125 cases. Chest 1993; 104: 1482-1485.

8. Paladine W, Cunningham TJ, Sponzo R, Donavan M, Olson K, Horton J. Intracavitary bleomycin in the management of malignant effusions. Cancer 1976; 38: 19031908.

9. Kaplan EL, Meier P. Nonparametric estimation from incomplete observation. J Am Stat Assoc 1958; 53: 457-481.

10. Mantel N. Evaluation of survival data and two new rank order statistics arising in its consideration. Cancer Chemother Rep 1966; 50: 163-170.

11. Zalonik AJ, Oswald SG, Langin M. Intrapleural tetracycline in malignant pleural effusions. A randomized study. Cancer 1983; 51: 752-755.

12. Gravelyn TR, Michelson MK, Gross BH, Sitrin RG. Tetracycline pleurodesis for malignant pleural effusions. A 10 years retrospective study. Cancer 1987; 59: 1973-1977.

13. Sherman S, Grady KJ, Seidman JC. Clinical experience with tetracycline pleurodesis of malignant pleural effusions. South Med J 1987; 80: 716-719.

14. Bitran JD, Brown C, Desser RK, Nozloff MF, Shapiro $\mathrm{C}$, Billings AA. Intracavitary bleomycin for the control of malignant effusions. J Surg Oncol 1981; 16: 273-277.

15. Ostrowski MJ. An assessment of the long-term results of controlling the reaccumulation of malignant effusions using intracavitary bleomycin. Cancer 1986; 57: 721-727.

16. Antony VB, Rothfuss KJ, Godbey SW, Sparks JA, Hott JW. Mechanism of tetracycline-hydrochloride-induced pleurodesis. Am Rev Respir Dis 1992; 146: 1009-1013.

17. Vargas FS, Wang NS, Teixeira LR, Carmo AO, Silva LMMF, Light RW. Corynebacterium parvum versus tetracycline as pleural sclerosing agents in rabbits. Eur Respir J 1995; 8: 2174-2177.

18. Vargas FS, Wang NS, Lee HM, Gruer SE, Sassoon CSH, Light RW. Effectiveness of bleomycin in comparison to tetracycline as pleural sclerosing agent in rabbits. Chest 1993; 104: 1582-1584.

19. Martínez-Moragón E, Aparicio J, Sanchis J, et al. Pleurodesis con tetraciclinas en el tratamiento del derrame pleural maligno. Estudio retrospectivo de 91 casos. Med Clin (Barc) 1993; 101: 201-204. 